\title{
The effects of urease immobilization on the transport characteristics and protein adsorption capacity of cellulose acetate based hemodialysis membranes
}

\author{
Filiz Yasar Mahlicli · Sacide Alsoy Altinkaya
}

Received: 26 November 2008/ Accepted: 5 May 2009/Published online: 26 May 2009

(C) Springer Science+Business Media, LLC 2009

\begin{abstract}
In this study, cellulose acetate (CA) based hemodialysis membranes were prepared by a dry phase inversion method and the influences of urease immobilization on the clearing performance and protein adsorption capacity of the membranes were investigated. Permeation experiments have shown that modification of CA membranes with urease immobilization not only enhanced the transport rate of urea but also increased the permeation coefficients of uric acid and creatinine by changing the structure of the membrane. Furthermore, the protein adsorption capacity of the CA membranes decreased. On the other hand, the mechanical strength of the modified CA membrane did not change significantly compared with that of the unmodified one. A mathematical model was derived to determine the rate of mass transfer of urea through modified CA membranes. Model predictions along with the experimental data suggest that urease immobilization can be used as an alternative method in preparing CA based hemodialysis membranes with improved transport characteristics and biocompatibility through reduced protein adsorption capacities.
\end{abstract}

\section{Introduction}

Hemodialysis is a frequently used clinical therapy for the treatment of chronic renal failure in which removal of metabolic toxic compounds takes place in an artificial

F. Y. Mahlicli · S. A. Altinkaya ( $\square)$

Department of Chemical Engineering, Izmir Institute of

Technology, Gulbahçe Koyu, 35430 Urla, Izmir, Turkey

e-mail: sacidealsoy@iyte.edu.tr kidney containing a membrane. Hemodialysis membranes are the most important elements of a dialysis unit and should have high permeability and low protein adsorption capacity, hence, enough biocompatibility in order to decrease the treatment time and prevent undesirable reaction with blood. Most of the hemodialysis membrane materials are hydrophobic in nature and allow protein adsorption on the surface easily due to hydrophobic interaction between membrane surface and protein molecules [1]. Protein adsorption does not only cause reductions in solutes permeation characteristics but it can also be followed by the activation of different defense systems in blood [1].

Although many techniques are proposed, surface modification is a commonly used approach to create membrane surfaces of biomedical devices which resist to protein adsorption. To increase hydrophilic nature of the blood contacting membranes, numerous surface modification methods have been suggested which can be summarized as follows: 1) blending hydrophilic polymers such as 2methacryloyloxyethyl phosphorylcholine (MPC) [2-8], polyvinylpyrrolidone (PVP) [9, 10], or polyethylene oxide (PEO) $[11,12]$ into the membrane forming solution, 2) grafting hydrophilic groups such as polyethylene glycol by UV-irradiation [13-15] or low temperature plasma technique [16-19], 3) graft copolymerization of monomers [20-23], 4) coating with hydrophilic polymers or copolymers [24-29]. Hemodialysis membranes were also immobilized with low molecular weight anticoagulant heparin to decrease protein adsorption capacities, hence, to improve hemocompatibilities [30-37]. Lin et al. have found that adsorption of human serum albumin and human plasma fibrinogen on polyacrylonitrile membrane decreased when chitosan/heparin polyelectrolyte complex was immobilized on the surface [37]. This was attributed to electrostatic 
repulsion between $\mathrm{SO}_{3}{ }^{-}$and $\mathrm{COO}^{-}$groups on heparin and negatively charged proteins in normal blood circumstance (pH 7.4). An alternative approach to membrane surface modification is protein immobilization on the hemodialysis membranes [38, 39]. Zhao et al. modified polysulfone membranes by immobilizing single-strand DNA onto their surfaces with UV-irradiation. Although hydrophilicity of the DNA immobilized membranes increased significantly, amount of model protein, bovine serum albumin, adsorbed on the membranes did not decrease. This was explained by strong hydrogen bonds formed between DNA and BSA molecules [38]. Liu et al. covalently immobilized plasma proteins onto polyacrylonitrile membranes to evaluate the hemocompatibility and anaphylatoxin formation [39]. Their results have shown that amount of fibrinogen adsorption increased with the immobilization of plateletadhesion-promoting protein. On the other hand, fibrinogen adsorption capacity of the PAN membranes decreased significantly when platelet-adhesion-inhibiting protein, human serum albumin, was used as a model protein for surface modification.

There has also been interest in surface modification techniques to improve the selectivity and permeability of the membranes. Among these techniques, a promising approach is enzyme immobilization on the hemodialysis membranes, however, only a few studies exist in the literature on this method [40, 41]. Yang and Lin immobilized urease enzyme on polyacrylonitrile hollow fibers by using glutaraldehyde and investigated the influences of concentration of glutaraldehyde, $\mathrm{pH}$ and temperature on the catalysis of urea [40]. The results of in vitro dialysis experiments have shown that the rate of removal of urea from the blood side with an urease immobilized dialyzer is almost 3 times faster than that obtained with a regular dialyzer.

In the current work, we prepared asymmetric cellulose acetate (CA) based hemodialysis membranes through dry phase inversion method and modified them by blending urease enzyme directly into the casting solution. The influence of the casting composition on the permeation rates and the mechanical properties of unmodified membranes was determined. Based on these results, appropriate composition of the membrane forming solution was chosen for urease immobilization. Transport rates of model toxic compounds, urea, uric acid and creatinine, through blend membrane were compared to those of unmodified CA membrane. In addition, the effect of enzyme immobilization on the protein adsorption capacity and the mechanical properties of the CA membranes was investigated. A mathematical model was derived to determine the rate of mass transfer of urea through modified CA membranes. To our knowledge, this is the first study illustrating the use of enzyme immobilization technique not only for enhancing transport rates but also for improving biocompatibility of hemodialysis membranes through the reduction of protein adsorption capacity of these membranes.

\section{Materials and methods}

\subsection{Materials}

Cellulose acetate (CA) with a molecular weight of $50000 \mathrm{~g} / \mathrm{mol}$ and an acetyl content of $39.8 \%$ was purchased from Sigma. Acetone, bovine serum albumin (MW 65000), urea (MW 60.06), creatinine (MW 113.12) and uric acid (MW 168.11) were also purchased from Sigma.

Urease (E.C.3.5.1.5) from jack beans and $\mathrm{H}_{2} \mathrm{NaPO}_{4}$, were purchased from Fluka. $\mathrm{Na}_{2} \mathrm{HPO}_{4}$, used for buffer solutions was purchased from Riedel. Phenol, sodiumnitroprusside dihydrate, sodium-hypochlorite were obtained from Merck, acetic acid was obtained from Aldrich and $\mathrm{NaOH}$ was purchased from Sigma. Water used in the experiments was distilled ion-exchanged water.

\subsection{Preparation of the membranes}

The cellulose acetate was dissolved in acetone, water was added and the solution was stirred for $6 \mathrm{~h}$ until it became homogeneous. The solution was left standing for $18 \mathrm{~h}$ to eliminate bubbles, then, cast onto $10 \mathrm{~cm} \times$ $24 \mathrm{~cm}$ glass substrate with the aid of an automatic film applicator (Model $1133 \mathrm{~N}$, Sheen Instrument Ltd.) at a speed of $100 \mathrm{~mm} / \mathrm{s}$. The initial thickness of the cast film was adjusted by a four sided applicator with the gap size of $300 \mu \mathrm{m}$. Immediately after casting, the support was transferred into an environmental chamber (Model $\mathrm{CH} 250$, Challenge Series-Angelantoni Industrie, Italy) where the solution was dried for $2 \mathrm{~h}$ at $25^{\circ} \mathrm{C}$ and $40 \%$ relative humidity. Membranes were allowed to dry further for a period of $24 \mathrm{~h}$ in a vacuum oven maintained at $100^{\circ} \mathrm{C}$. They were then kept in a desiccator until their use.

To prepare immobilized urease-membranes, $0.5 \mathrm{~g}$ of cellulose acetate was dissolved in $10.2 \mathrm{ml}$ of acetone and $50 \mathrm{mg}$ of urease was dissolved in $1.45 \mathrm{ml}$ of water. The polymer and enzyme solution were mixed and stirred for $30 \mathrm{~min}$. Then, the solution was cast on a glass substrate with a knife of $300 \mu \mathrm{m}$ gap and dried in the environmental chamber for $2 \mathrm{~h}$ under $25^{\circ} \mathrm{C}$ temperature and $40 \%$ relative humidity. In order to remove soluble and weakly bonded enzyme, membranes were rinsed with $10 \mathrm{ml}$ distilled water during $30 \mathrm{~min}$ by changing the rinsing water for every $10 \mathrm{~min}$. Urease desorption during the operation was checked by immersing the membrane in $25 \mathrm{ml} \mathrm{Na-phosphate} \mathrm{buffer}$ solution maintained at 
$37^{\circ} \mathrm{C}$. During $4 \mathrm{~h}$ immersion period, the urease content in the solution was determined by measuring the absorbance at $285 \mathrm{~nm}$ with a UV-spectrophotometer (PerkinElmer, Model No: Lambda 45). All immobilized ureasemembranes were kept in the refrigerator at $4{ }^{\circ} \mathrm{C}$ until use. The compositions of the initial casting solutions used to prepare different membranes are shown in Table 1.

\subsection{Determination of immobilized urease activity}

Enzyme activity was calculated by measuring the amount of ammonia produced enzymatically where urease can catalyze the hydrolysis of urea as follows:

$\mathrm{H}_{2} \mathrm{NCONH}_{2}+2 \mathrm{H}_{2} \mathrm{O} \stackrel{\text { urease }}{\longrightarrow} 2 \mathrm{NH}_{3}+\mathrm{CO}_{2}$

The amount of ammonia produced was determined spectrophotometrically using the method reported by Weatherburn [42]. In this method, two reagents were prepared according to the following procedure: Reagent A was prepared by dissolving $5 \mathrm{~g}$ of phenol and $25 \mathrm{mg}$ of sodium-nitroprusside in $500 \mathrm{ml}$ distilled water, while $2.5 \mathrm{~g}$ of sodium hydroxide was dissolved in $4.2 \mathrm{ml}$ of sodium-hypochlorite and completed to $500 \mathrm{ml}$ of distilled water to prepare reagent $\mathrm{B}$.

The immobilized activity of urease was determined by contacting $7 \mathrm{~cm}^{2}$ catalytic membrane with $25 \mathrm{ml}$ of $100 \mathrm{mM}$ urea solution that was prepared in $0.05 \mathrm{M} \mathrm{pH} 7.4$ phosphate buffer solution. Before immersing the membranes, urea solution was incubated for $30 \mathrm{~min}$ at $37^{\circ} \mathrm{C}$. The membrane was kept in the solution for a period of $90 \mathrm{~min}$ and during this period, the solution was maintained at $37^{\circ} \mathrm{C}$ and continuously stirred with a speed of $200 \mathrm{rpm}$. After reaction started, $1 \mathrm{ml}$ sample was taken at $45 \mathrm{~min}$ and $10 \%$ acetic acid solution was added in order to stop the reaction. $20 \mu \mathrm{l}$ volume from this sample was pipetted into three tubes, then, $5 \mathrm{ml}$ of reagent $\mathrm{A}$ was added, stirred sufficiently and $5 \mathrm{ml}$ reagent $\mathrm{B}$ was mixed thoroughly. The test tubes were incubated at $37^{\circ} \mathrm{C}$ for a period of $20 \mathrm{~min}$ to observe color change which corresponds to ammonia evolution. The absorbance of the solution was then measured at $625 \mathrm{~nm}$ against a $20 \mu \mathrm{l}$ phosphate buffer solution.
The activity of urease was calculated from the production rate of $\mathrm{NH}_{3}$ in 45 min as follows:

Activity $=\left(\frac{\text { Number of moles of } \mathrm{NH}_{3} \text { produced in } 45 \mathrm{~min}}{(45 \mathrm{~min}) \times\left(\mathrm{cm}^{2} \text { of the membrane }\right)}\right)$

To determine stability of immobilized urease in buffer, four pieces of membranes were immersed into $25 \mathrm{ml}$ of $0.05 \mathrm{M}$ phosphate buffer solution at $\mathrm{pH} 7.4$ and $37^{\circ} \mathrm{C}$. The solution was stirred thoroughly and the membrane samples were removed from the solution at 60, 120, 180 and 240 min successively. The stability of immobilized urease during dry storage was also determined by storing the membranes in dry form at $4{ }^{\circ} \mathrm{C}$ for about 8 weeks. The activity of urease immobilized in both wet and dry-stored membranes was measured using same procedure described above.

Kinetic parameters of the enzymatic reaction were determined by immersing three pieces of membranes with an area of $5 \mathrm{~cm}^{2}$ into $25 \mathrm{ml}$ of urea solution that was prepared in $0.05 \mathrm{M} \mathrm{pH} 7.4$ phosphate buffer solution, previously incubated at $37^{\circ} \mathrm{C}$. The urea concentration in the reaction mixture was changed between 1 and $150 \mathrm{mM}$. The kinetic parameters were determined through LineweaverBurk plots.

\subsection{Permeation experiments}

Permeation experiments were carried out in a side by side diffusion cell (Permegear Membrane Transport Systems) as shown in Fig. 1. The membrane with an area of $1.8 \mathrm{~cm}^{2}$ was placed between two chambers, each with a volume of $6 \mathrm{ml}$. The left-side (Donor) chamber was filled with phosphate buffer ( $\mathrm{pH}$ 7.4) containing desired amount of solute, while the right-side (Receiver) chamber was only filled with phosphate buffer ( $\mathrm{pH}$ 7.4). The solution in each chamber was stirred sufficiently to eliminate concentration gradient and temperature was maintained constant at $37^{\circ} \mathrm{C}$ by circulating water through the jacket which surrounds the chambers. Samples were removed from each chamber at given time intervals and the concentration of uric acid was

Table 1 Morphological characteristics of modified and unmodified CA membranes

\begin{tabular}{|c|c|c|c|c|c|c|c|c|}
\hline \multirow{2}{*}{$\begin{array}{l}\text { Code of the } \\
\text { membrane }\end{array}$} & \multicolumn{4}{|c|}{ Weight percentage of components (wt $\%)$} & \multirow{2}{*}{$\begin{array}{l}\text { Thickness of } \\
\text { membrane }(\mu \mathrm{m})\end{array}$} & \multirow{2}{*}{$\begin{array}{l}\text { Percentage of dense } \\
\text { skin layer }(\%)\end{array}$} & \multirow{2}{*}{$\begin{array}{l}\text { Average pore } \\
\text { size }(\mu \mathrm{m})\end{array}$} & \multirow[t]{2}{*}{ Porosity $(\%)$} \\
\hline & $\mathrm{CA}$ & Acetone & Water & Urease & & & & \\
\hline CAI & 5 & 80 & 15 & 0 & 27.94 & 13.44 & 1.15 & 67 \\
\hline CAII & 10 & 80 & 10 & 0 & 19.66 & 17.10 & 0.53 & 31 \\
\hline CAIII & 15 & 80 & 5 & 0 & 19.16 & 29.96 & 0.42 & 19 \\
\hline CAI-U & 5 & 80 & 14.5 & 0.5 & 16.71 & 2.62 & 1.37 & 68 \\
\hline
\end{tabular}


determined by directly measuring its natural absorbance at $285 \mathrm{~nm}$. Urea and creatinine concentrations were evaluated using commercial enzymatic kits (BT Product, Turkey). For that purpose, samples were mixed with $1 \mathrm{ml}$ of reagent and allowed to react. Then, the concentration of urea was determined from the difference in absorbance readings at $340 \mathrm{~nm}$ taken 30 and $90 \mathrm{~s}$ after mixing while the difference in absorbance readings at $510 \mathrm{~nm}$ taken 60 and $180 \mathrm{~s}$ after mixing was used to determine creatinine concentration.

In the case of permeation experiments conducted with immobilized urease-membranes, the concentration of ammonia in both donor and receiver compartments was determined by the method described in Sect. 2.3. Then, urease was added into the solution to completely decompose the unreacted urea into ammonia. The concentration of nondecomposed urea in each compartment was then determined from the difference in concentrations of ammonia measured before and after urea was decomposed completely with urease.

\subsection{Protein adsorption experiments}

Protein adsorption experiments were also carried out in the diffusion cell shown in Fig. 1. The membrane with an area of $1.8 \mathrm{~cm}^{2}$ was placed between two chambers. The donor compartment was filled with bovine serum albumin (BSA) solution with a concentration of $1 \mathrm{mg} / \mathrm{ml}$ prepared in $0.05 \mathrm{M}, \mathrm{pH} 7.4$ phosphate buffer solution. The receiver compartment was only filled with phosphate buffer $(\mathrm{pH}$ 7.4). Both compartments were maintained at $37^{\circ} \mathrm{C}$ for at least $24 \mathrm{~h}$. During this period, $100 \mu \mathrm{l}$ samples were taken at given time intervals and BSA concentration in the solution was determined using a rapid and sensitive Bradford method which utilizes the principle of proteindye binding [43].

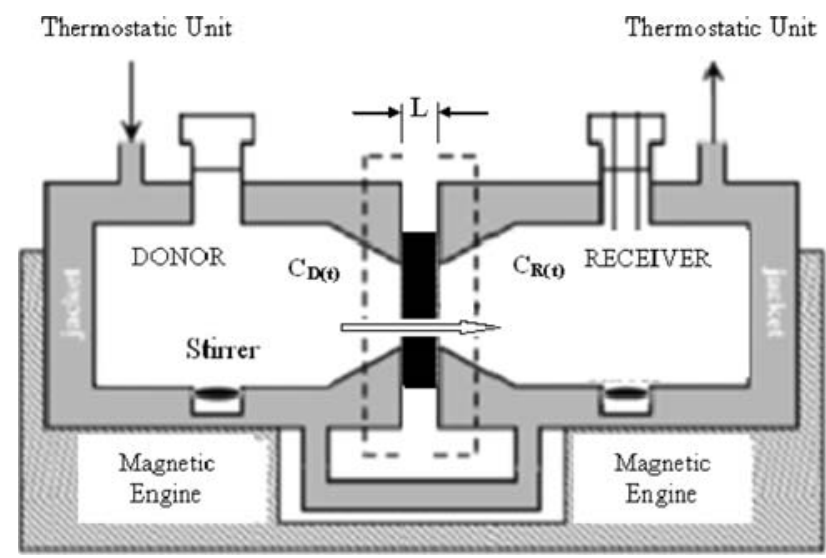

Fig. 1 Experimental set-up used for permeation experiments

\subsection{Characterization studies}

\subsubsection{Measurement of tensile strength}

The tensile strength of the membranes was measured using a Shimadzu AG-I-250 KN testing machine. The membranes were strained at constant rates of 0.25 and $0.5 \mathrm{~mm} /$ min until failure. The test method and sample preparation were in accordance with ASTM D 882-02 standard. At least five test samples with $10 \mathrm{~mm}$ in width and $5 \mathrm{~cm}$ in length were used for measurements. The tensile strength $(\delta)$ and the strain $(\sigma)$ were calculated using the following equations:

$\delta=\frac{F}{A} \quad \sigma=\frac{L-L_{o}}{L_{o}}$

where $F$ is the applied load, $A$ is the cross-sectional area of the specimen, $L_{o}$, is the original distance between gage marks and $L$ is the distance between gage marks at any time. Young's modulus was obtained from the initial linear part of $\delta$ versus $\sigma$ graph.

\subsubsection{Surface characterization}

The surface morphology of the membranes was examined by scanning electron microscopy (SEM) on a Philips XL30SFG model. The samples were coated with gold using a Magnetron Sputter Coating Instrument.

To determine porosity of the membranes, the samples were dried for $2 \mathrm{~h}$ at $100^{\circ} \mathrm{C}$ under vacuum and weighed in dry form $\left(w_{d r y}\right)$. Then, they were immersed in water and kept there until all pores were filled with water. Finally, the weight of the samples in water $\left(w_{\text {inwater }}\right)$ and in wet form $\left(w_{\text {wet }}\right)$ after removing water was determined. Based on these measurements, the total volume of the pores is calculated from the difference between the volume of CA $\left(V_{1}\right)$ and volume of CA membrane $\left(V_{2}\right)$ as follows:

$V_{1}=\frac{w_{d r y}}{\rho_{p}} \quad V_{2}=\frac{w_{d r y}}{\rho_{m}} \quad V_{\text {pores }}=V_{2}-V_{1}$

where $\rho_{m}$ is the density of the membrane

$\rho_{m}=\frac{\rho_{\text {water }} w_{\text {dry }}}{w_{\text {wet }}-w_{\text {inwater }}}$

and $\rho_{\text {water }}$ and $\rho_{p}$ are the densities of pure water and polymer, respectively. The porosity of the membrane, $\varepsilon$, is then calculated from the ratio of the volume of the pores to that of the membrane.

$\varepsilon=\frac{V_{\text {pores }}}{V_{2}}$ 


\section{Theory}

To study the transport of solutes, the enzyme immobilized membrane with a thickness of $L$ and area of $A$ is placed between two compartments of the diffusion cell shown in Fig. 1. The solution in each compartment is well mixed to eliminate concentration gradients, thus, the concentration of solute in each compartment only changes with time. It is assumed that mass transfer through the membrane is one dimensional, dominantly by diffusion and steady-state condition is reached in a short period of time in the membrane since the volume of the membrane is very small compared to the volume of the solution in each compartment. Furthermore, it is assumed that no enzyme desorbs during the experiment and the enzymatic reaction takes place homogeneously through the membrane and is described by a slight modification of Michaelis-Menten equation:

$r=\frac{V_{\max t}^{*} C_{s}}{K_{m}+C_{s}}$

where $C_{s}$ is the concentration of the substrate, $K_{m}$ is the substrate concentration required to reach half of the maximum reaction rate and $V_{\max t}^{*}$ takes into account enzyme inactivation which may occur during the permeation process and it usually follows an exponential function [44].

$V_{\max t}^{*}=V_{\max } e^{-k t}$

In Eq. 7, $k$ represents the inactivation constant and it is clear that when there is no inactivation, $V_{\max t}^{*}$ corresponds to the maximum reaction rate, $V_{\max }$, in the original Michaelis-Menten equation. If it is assumed that $K_{m} \gg C_{s}$, then the rate expression becomes linear

$r=\frac{V_{\max t}^{*} C_{s}}{K_{m}}$

and the species continuity equation for the substrate through the membrane is given by the following equation.

$D_{s m} \frac{d^{2} C_{s}}{d x^{2}}-\frac{V_{\max t}^{*}}{K_{m}} C_{s}=0$

where $D_{s m}$ is the diffusivity of the substrate in the membrane. Equation 9 is a linear, homogeneous, secondorder differential equation with constant coefficients. Its general solution is given by Eq. 10 .

$C_{s}(x)=C_{1} e^{m x}+C_{2} e^{-m x}$

where

$m=\sqrt{\frac{V_{\max t}^{*}}{K_{m} D_{s m}}}$

and $C_{1}$ and $C_{2}$ are constants which are evaluated from the following boundary conditions $x=0 \quad C_{s}=C_{M 1} \quad x=L \quad C_{s}=C_{M 2}$

The concentrations at the membrane surfaces are related to those in the donor and receiver compartments by assuming a linear equilibrium relationship.

$C_{M 1}=K C_{D} \quad C_{M 2}=K C_{R}$

where $K$ is the partition coefficient of the solute between the membrane and the adjacent phase. Then, the concentration profile of the solute through the membrane is given as follows:

$C_{s}(x)=\left(\frac{C_{M 2}-C_{M 1} e^{-m L}}{e^{m L}-e^{-m L}}\right) e^{m x}-\left(\frac{C_{M 2}-C_{M 1} e^{m L}}{e^{m L}-e^{-m L}}\right) e^{-m x}$

In order to calculate the solute concentrations in the donor and receiver compartments, overall mass balances are written

$V_{D} \frac{d C_{D}}{d t}=(-J A)_{x=0}$

$V_{R} \frac{d C_{R}}{d t}=(+J A)_{x=L}$

based on the assumptions that the solution is well stirred and no enzyme desorbs during the experiment, thus, there is no enzymatic reaction in the solution. In Eqs. 15 and 16, $t$ represents time and $V_{D}, V_{R}, C_{D}$ and $C_{R}$ are the liquid volumes and solute concentrations in the donor and receiver compartments, respectively. The solute fluxes at the membrane surfaces are calculated using Fick's law and the concentration profile of the solute through the membrane (Eq. 14). The results are given in the following equations.

$$
\begin{aligned}
(J)_{x=0} & =-\left.D_{s m} \frac{d C_{s}}{d x}\right|_{x=0} \\
& =D_{s m}\left\{\frac{C_{M 1} e^{m L}-C_{M 2}}{e^{m L}-e^{-m L}}+\frac{C_{M 1} e^{-m L}-C_{M 2}}{e^{m L}-e^{-m L}}\right\} m \\
(J)_{x=L} & =-\left.D_{s m} \frac{d C_{s}}{d x}\right|_{x=L} \\
& =D_{s m}\left\{\frac{C_{M 1} e^{m L}-C_{M 2}}{e^{m L}-e^{-m L}} e^{-m L}+\frac{C_{M 1} e^{-m L}-C_{M 2}}{e^{m L}-e^{-m L}} e^{m L}\right\} m
\end{aligned}
$$

Finally, if Eqs. 17 and 18 are inserted into Eqs. 15 and 16

$$
\frac{d C_{D}}{d t}=-\frac{A}{V_{D}} D_{s m}\left\{\frac{C_{M 1} e^{m L}-C_{M 2}}{e^{m L}-e^{-m L}}+\frac{C_{M 1} e^{-m L}-C_{M 2}}{e^{m L}-e^{-m L}}\right\} m
$$

$\frac{d C_{R}}{d t}=\frac{A}{V_{R}} D_{s m}\left\{\frac{C_{M 1} e^{m L}-C_{M 2}}{e^{m L}-e^{-m L}} e^{-m L}+\frac{C_{M 1} e^{-m L}-C_{M 2}}{e^{m L}-e^{-m L}} e^{m L}\right\} m$ 
and if Eqs. 19 and 20 are integrated numerically, the concentrations of solute in the donor and receiver compartments are obtained.

In the case of noncatalytic membranes, effective permeation coefficient of the solute, $P_{\text {eff }}$, through the membrane is calculated from the slope of the $\ln \frac{C_{D i}-C_{R i}}{C_{D}-C_{R}}$ versus time graph [45].

$\ln \frac{C_{D i}-C_{R i}}{C_{D}-C_{R}}=\beta P_{e f f} t$

where $C_{D i}$ and $C_{R i}$ represent the initial solute concentrations in donor and receiver compartments, respectively and the geometric constant $\beta$ and $P_{\text {eff }}$ are given by the following equations:

$$
\begin{aligned}
& \beta=\left[\frac{1}{V_{D}}+\frac{1}{V_{R}}\right] A \\
& P_{\text {eff }}=\frac{D_{s m} K}{L}
\end{aligned}
$$

\section{Results and discussion}

\subsection{The influence of casting composition on the} permeation of model solutes through unmodified cellulose acetate membranes

Typical experimental results for the clearance of urea, uric acid and creatinine through CAIII membrane are shown in Fig. 2. The data are presented in terms of solute concentration difference measured in donor and receiver compartments, normalized with respect to the concentration difference at the beginning, as a function of time. The urea concentration decreases most rapidly due to fast diffusion of this small molecular weight solute. Each data set in this figure were fitted to a linear equation and the linearity of the data was found to be perfect determined with $R^{2}$ values greater than 0.98 . The permeation coefficients were evaluated from Eq. 21 by dividing the slope of the fitted data by the constant $\beta$ value of 0.59 . Figure 3 shows that the permeation coefficients decrease exponentially with the increased molecular weight of the solutes and the increased CA concentration in the casting solution. This is mainly caused by the change in final structure of the membranes from porous to dense one as shown by SEM pictures in Figs. 4, 5, and 6. All of the membranes have an asymmetric structure with the pore size larger on the glass contacting surface than that on the air-facing surface. As listed in Table 1, the results obtained from the analysis of SEM pictures indicate that average pore sizes and porosities decrease while the percentage of dense skin layer increase by increasing CA concentration in the casting solution. Macrovoids present in CAI membrane lead to larger thickness for this membrane compared to CAII and CAIII membranes. Macrovoid formation in CA membranes prepared with dry casting method was also reported in other studies $[46,47]$.

\subsection{Characterization of immobilized urease-CA membranes}

CAI membrane prepared with 5\% CA in the solution was selected for modification due to high solute permeation rates through this membrane and its sufficient mechanical strength. Modified CAI membranes (CAI-U) were prepared by blending $0.5 \%$ urease enzyme directly into the casting solution. Immersion of these membranes in the Na-phosphate buffer solution at $37^{\circ} \mathrm{C}$ during $4 \mathrm{~h}$ of typical hemodialysis time did not cause desorption of urease from the membranes into the solution. This simply indicated that the blending technique for immobilization of urease is simple, yet provides sufficient entrapment of the enzyme within the polymeric matrix. In addition to desorption study, immobilized urease-membranes were also characterized in terms of wet/dry storage stabilities and their kinetic parameters. The results are discussed in the following sections.

\subsubsection{Determination of stability of immobilized urease}

The stability of immobilized urease activities was determined in both wet and dry conditions. Figure 7 shows the change in the relative activity of immobilized urease when the CA membrane was stored at $37^{\circ} \mathrm{C}$ in a $\mathrm{pH} 7.4$ phosphate buffer solution. Activity was measured during $4 \mathrm{~h}$ of time period which corresponds to typical hemodialysis time. The results have shown that $51 \%$ of the initial activity was lost within $4 \mathrm{~h}$. Lin and Yang [41] found that urease immobilized on polyacrylonitrile hollow fibers retained $90 \%$ of its initial activity within 20 days when stored at $\mathrm{pH}$

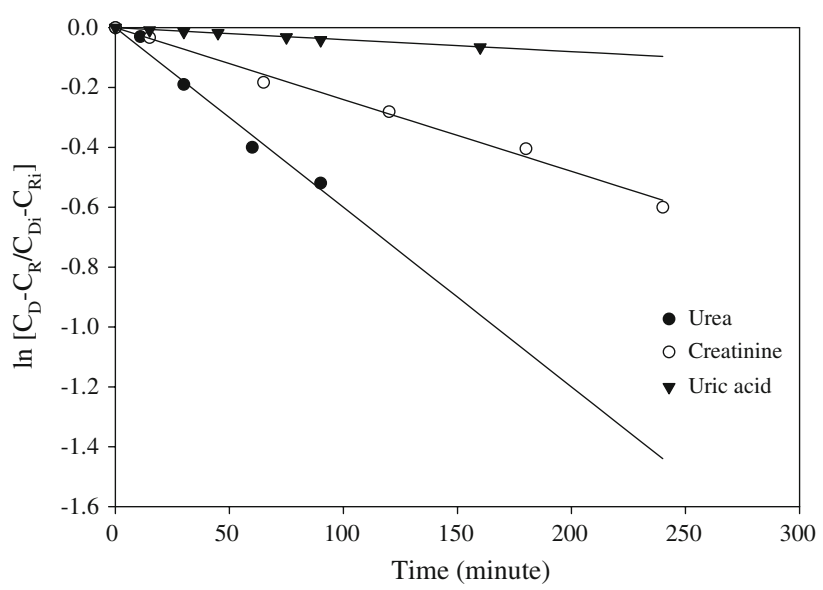

Fig. 2 The change of $\ln \frac{C_{D}-C_{R}}{C_{D i}-C_{R i}}$ with respect to time for the permeation of urea, uric acid and creatinine through CAIII membrane 


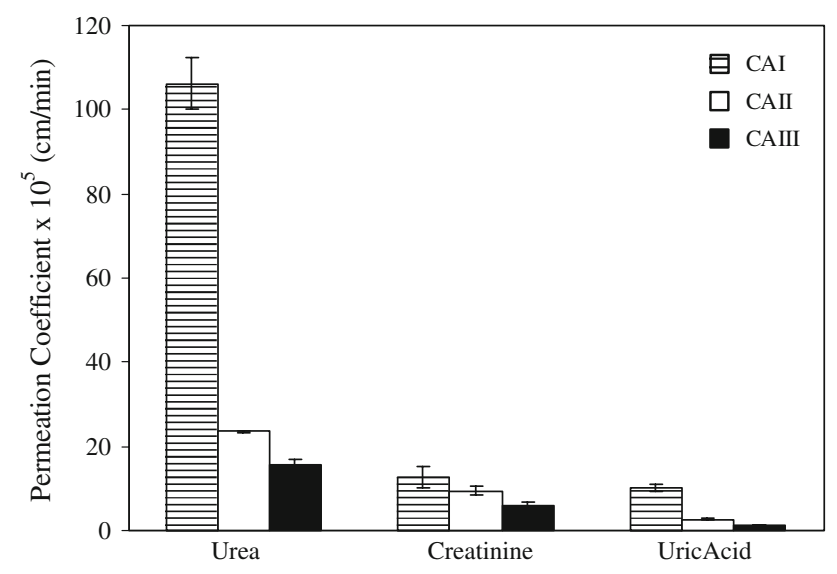

Fig. 3 The permeation coefficients of urea, uric acid and creatinine through CAI, CAII and CAIII membranes

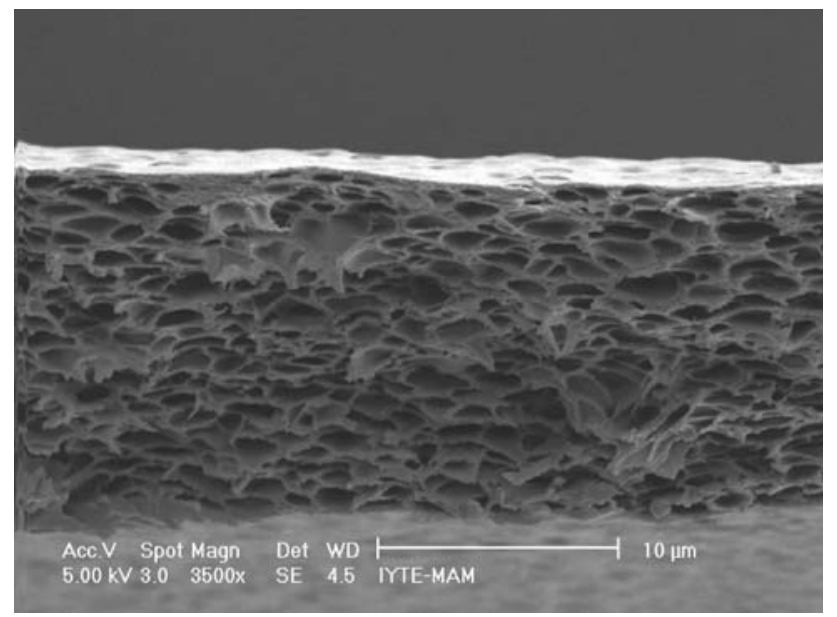

Fig. 4 SEM picture of CAI membrane, magnification $3500 \times$

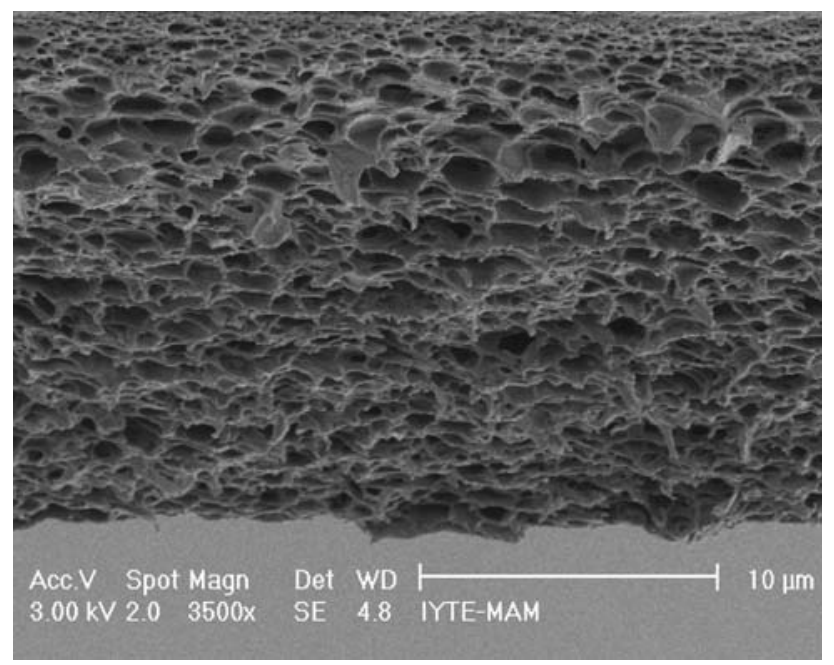

Fig. 5 SEM picture of CAII membrane, magnification $3500 \times$

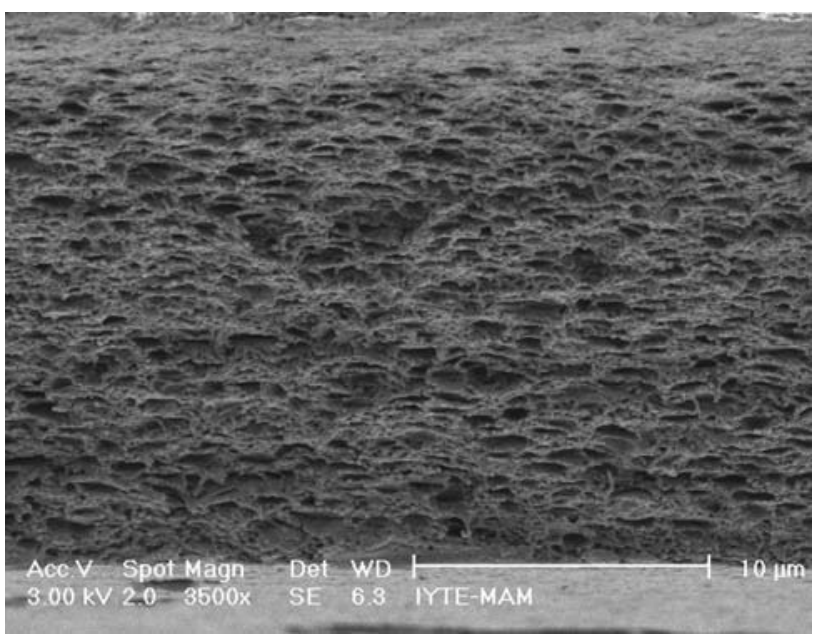

Fig. 6 SEM picture of CAIII membrane, magnification $3500 \times$

7 and $4^{\circ} \mathrm{C}$. Much higher urease stability observed in their study is due to immobilization of enzyme with a strong covalent bonding. On the other hand, the difference in stability can also be explained by different polymeric supports and storage temperatures used in our and their studies. Considering the fact that reuse of hemodialysis membranes is forbidden in many countries, the long term stability of urease immobilized on hemodialysis membranes does not seem to be critical. The change in relative activity of immobilized urease when $\mathrm{CA}$ membrane was stored at $4^{\circ} \mathrm{C}$ in a dry form is also shown in Fig. 7. According to this figure, dry-stored immobilized urease retained its activity above $85 \%$ for almost 60 days, much higher than that of wet-stored urease, since temperature during dry storage is lower than that of wet storage. In addition, phosphate buffer solution contributes to the faster inactivation of urease. Similar results were reported in the literature by some other groups. Krajewska et al. [48] reported $30 \%$ lost in the initial activity of wet-stored immobilized urease within 10 days and $20 \%$ lost over a period of 60 days when immobilized urease was stored in a dry form. Lin and Yang [49] found that dry-stored cholesterol oxidase (COD) retained its activity above $95 \%$ for 60 days, while the activity in wet form decreased sharply when it was stored for more than 3 days. The dry-storage stability of immobilized urease is an important factor for the economical use of immobilized urease-membranes in commercial hemodialysis units.

\subsubsection{Determination of kinetic parameters of immobilized urease}

Enzyme kinetic measurements were carried out for native and immobilized urease and the kinetic parameters are listed in Table 2. For each case, a linear relationship between $(1 / r)$ and $\left(1 / C_{s}\right)$ indicated by high $R^{2}$ value close to 


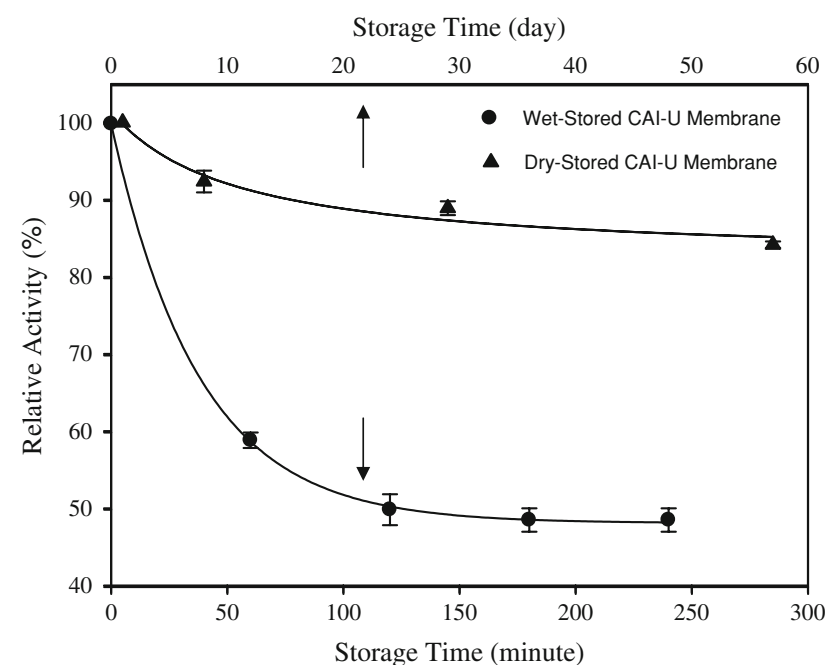

Fig. 7 The effect of storing time on the relative activity of urease immobilized in CAI membrane. Initial activity of urease $=1.18 \mu \mathrm{mol} \mathrm{NH} / 3$ min $\mathrm{cm}^{2}$. Membrane was stored in phosphate buffer solution at $\mathrm{pH} 7.4, T=37^{\circ} \mathrm{C}$ (wet-stored) and in dry form at $4^{\circ} \mathrm{C}$ (dry-stored)

1 demonstrates that the decomposition of urea by either native or immobilized urease follows the Michaelis-Menten type kinetics. $V_{\max }$ value of the urease immobilized in CA membranes is lower than that of the native urease. This can be explained by the inactivation of urease during immobilization and increased diffusional resistance encountered by the urea while it approaches to the catalytic sites. The adsorption of BSA on the CA membrane caused a decrease in the reaction rate of the immobilized urease as shown in Fig. 8. This may be due to a change in the location and number of electrostatic interactions created between enzyme and protein or simple steric blocking of the urease by adsorbed BSA which may have all affected the optimal configuration and resulting activity of immobilized urease. Lower catalytic activity of the BSA fouled CA membrane can also be explained by the inactivation of the enzyme during the fouling process.

\subsection{The influence of urease immobilization on the} transport rates of solutes through CA membranes

To determine the influence of urease immobilization on the solute transport rates, permeation experiments for three model compounds were performed with the initial

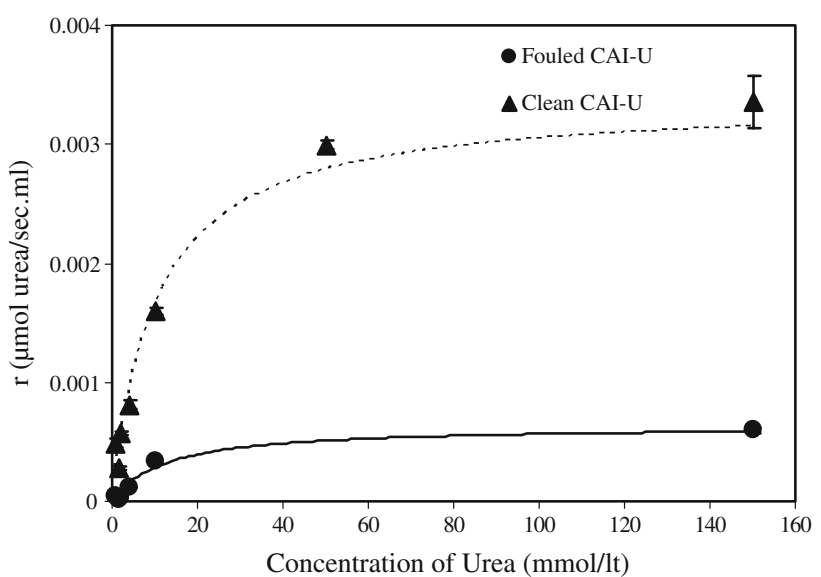

Fig. 8 The rate of reaction as a function of substrate concentration

concentrations used in the previous experiments. The data collected for creatinine and uric acid were evaluated with Eq. 21 to determine their permeation coefficients. The partition coefficients of these solutes were also measured from independent static sorption experiments which allowed to calculate diffusivities from Eq. 23. The results listed in Table 3 clearly indicate that diffusivities of both uric acid and creatinine through immobilized urease-CA membrane are slightly higher. This is caused by the change in structure of the membrane as illustrated in Fig. 9. The comparison of the structural properties of the modified and unmodified CAI membranes listed in Table 1 points out that urease immobilization caused a decrease in the thickness of the dense skin layer. When urease is blended into the casting solution, diffusion of acetone and water in the solution is hindered and evaporation becomes slower. Consequently, less amount of polymer and urease accumulate on the surface leading to thinner dense skin layer once all solvent and nonsolvent are removed. The total thickness of the membrane decreased with urease immobilization due to disappearance of macrovoids while average pore size and porosity did not change considerably. As a result, the resistance to diffusion of the uric acid and creatinine which are not decomposed by urease becomes smaller in modified CA membrane leading to faster diffusion rates.

Diffusivity of urea in the immobilized urease-membrane along with the enzyme inactivation constant, $k$, were regressed by minimizing the difference between the

Table 2 Kinetic data for decomposition of urea by native urease and immobilized urease in CA membrane

\begin{tabular}{llll}
\hline Michaelis-Menten constants & Native urease & CAI-U clean membrane & CAI-U fouled membrane \\
\hline$K_{m}(\mathrm{mmol} / \mathrm{l})$ & 13.7 & 10.4 & 12.2 \\
$V_{\max }(\mathrm{mmol} / \mathrm{s} \cdot \mathrm{l})$ & 0.01030 & 0.00337 & 0.00064 \\
$V_{\max } / K_{\mathrm{m}}(1 / \mathrm{s})$ & $75.2 \times 10^{-5}$ & $32.5 \times 10^{-5}$ & $5.2 \times 10^{-5}$ \\
$R^{2}$ & 0.99 & 0.98 & 0.98 \\
\hline
\end{tabular}


Table 3 The list of partition coefficients and diffusivities of model solutes

\begin{tabular}{lllll}
\hline Parameters & $\begin{array}{l}\text { Model } \\
\text { solute }\end{array}$ & $\begin{array}{l}\text { CAI clean } \\
\text { membrane }\end{array}$ & $\begin{array}{l}\text { CAI-U clean } \\
\text { membrane }\end{array}$ & $\begin{array}{l}\text { CAI-U fouled } \\
\text { membrane }\end{array}$ \\
\hline $\begin{array}{l}\text { Partition coefficient of Urea } \\
\left(\mathrm{cm}^{3} \text { solution } / \mathrm{cm}^{3} \text { membrane }\right)\end{array}$ & Urea & 401 & 3156 & 2442 \\
& Creatinine & 313 & 320 & 284 \\
$D \times 10^{10}\left(\mathrm{~cm}^{2} / \mathrm{s}\right)$ & Uric acid & 2146 & 2405 & 2391 \\
& Urea & 74.16 & 7.00 & 7.00 \\
& Creatinine & 11.33 & 12.01 & 8.25 \\
& Uric acid & 1.31 & 1.85 & 1.24 \\
\hline
\end{tabular}

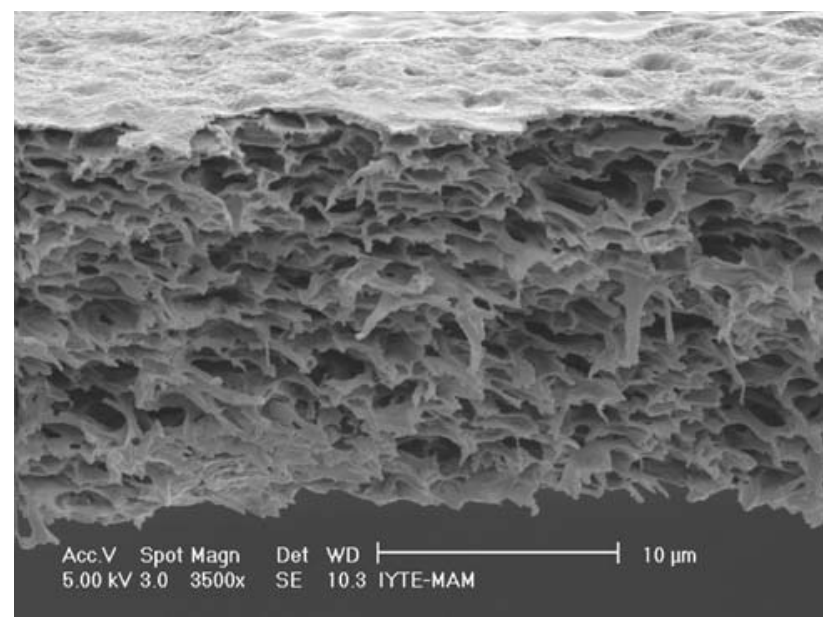

Fig. 9 SEM picture of modified CA membrane (CAI-U) with urease immobilization, magnification $3500 \times$

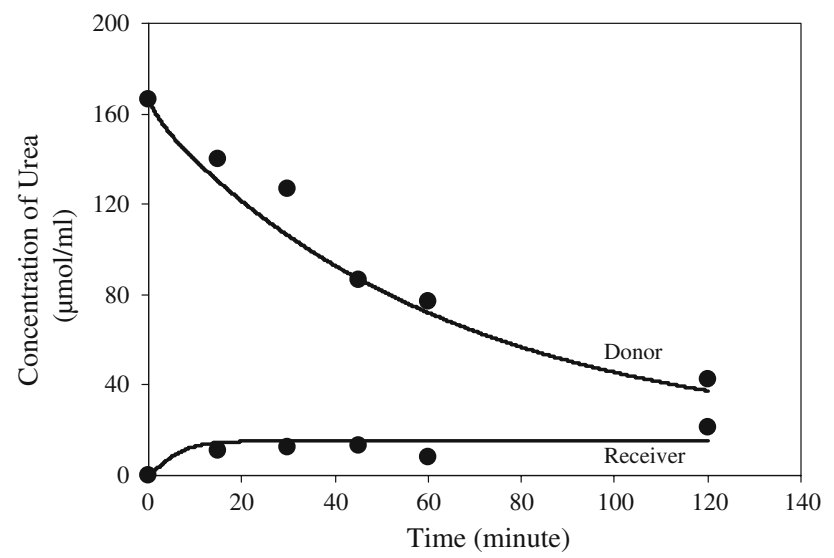

Fig. 10 The comparison of model predictions with the experimental data for the change of urea concentration in donor and receiver compartments with respect to time when immobilized urease-CA membrane was used. The symbols correspond to experimental data and the lines represent model predictions. The enzyme inactivation constant, $k$, regressed is $0.008 \mathrm{~min}^{-1}$

experimental data and model predictions as shown in Fig. 10. The mathematical model derived in this study provides a good correlation of the experimental data. The immobilization of urease into the CA membrane caused a decrease in the diffusivity of urea by a factor of 10 due to the fact that in the presence of urease, the affinity between the enzyme and urea leads to an increase in the diffusion pathway. Although, the diffusion rate of urea decreased, at the end of $2 \mathrm{~h}$, we obtained a 1.4-fold increase in the urea removal rate with the modified CA membrane since in this case, not only the rate of diffusion but also the rate of enzymatic reaction controls its removal rate. Figure 11 shows that at the beginning of the dialysis experiment, urea removal becomes slower with modified CA membrane. This simply indicates that the transport of urea is initially controlled by diffusion. After $40 \mathrm{~min}$ of the dialysis, no more urea removal occurs with unmodified CA membrane, while urea concentration continues to decrease when using immobilized urease-membrane. This result points out that at later times urea transport is dominantly controlled by enzymatic reaction. The dominant transport mechanism that influences the performance of the immobilized ureaseCA membrane can be determined by a dimensionless parameter called Thiele modulus which is defined as the ratio of the reaction rate and diffusion rate of the substrate [50].

$\phi=L\left(\frac{V_{\max o}}{D_{A B} K_{m}}\right)^{1 / 2}$

Using the data in Tables 2 and 3, Thiele modulus was calculated as 1.08 which supports the observation in Fig. 11 that the transport of urea through immobilized urease-CA membrane is governed both by its diffusion and decomposition. Compared to 1.4-fold increase in the urea removal rate with urease immobilization in our study, Lin and Yang [41] observed approximately 3 times increase when using immobilized urease-PAN membrane. Higher enhancement in urea clearance value obtained by this group is mainly due to different enzyme immobilization technique and the support type both of which strongly influence the initial activity and stability of the enzyme during its usage. 


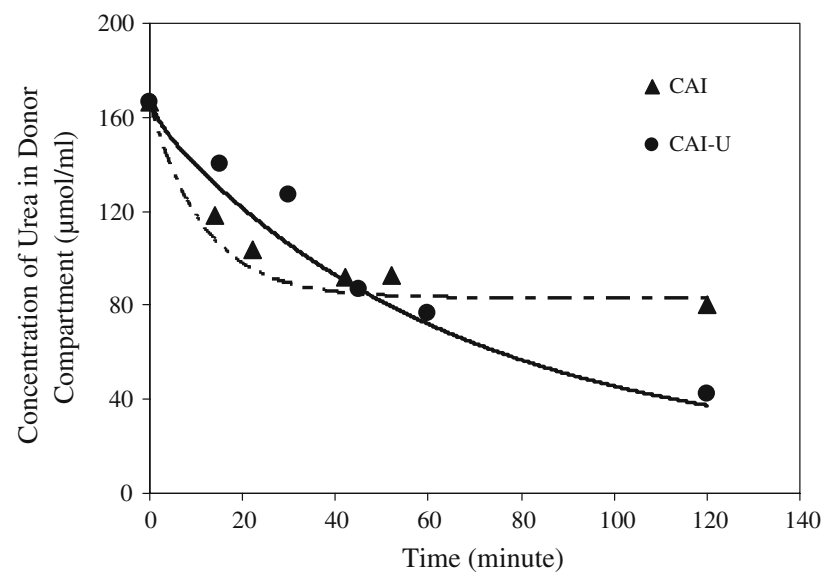

Fig. 11 The change of concentration of urea in donor compartment with respect to time. The symbols denote experimental data and lines correspond to model predictions

\subsection{The influence of urease immobilization on the protein adsorption capacity of CA membranes}

To determine protein adsorption capacities of both modified (CAI-U) and unmodified (CAI) CA membranes, the change in concentration of bovine serum albumin (BSA) in both donor and receiver compartments was followed. It was found that equilibrium was achieved within $24 \mathrm{~h}$ of period. Using equilibrium and initial concentrations in the donor compartment, amount of BSA adsorbed on the CAI$\mathrm{U}$ and CAI membranes were determined as 8.3 and $25.5 \mu \mathrm{g} / \mathrm{cm}^{2}$, respectively. The decrease in protein adsorption capacity of CA membrane with urease immobilization can be explained by the change in its surface hydrophilic character. During protein adsorption experiments, both urease enzyme and BSA are negatively charged since their isoelectric points (BSA: 4.9 and urease: 5) are lower than $\mathrm{pH}$ of the BSA solution adjusted to $\mathrm{pH}$ of the blood (7.4). Thus, urease enzyme located on the surface of the CA membrane repels BSA due to electrostatic interactions, as a result, amount of BSA adsorbed on the immobilized urease-membrane decreases. Considering the fact that total area of the hemodialysis membranes is large, threefold decrease in the protein adsorption capacity of the CA membrane with urease immobilization helps in improving its biocompatibility.

\subsection{The influence of protein fouling on transport rates of solutes through unmodified and immobilized urease-CA membranes}

To determine the influence of protein fouling on the transport rates of solutes, all permeation experiments were repeated with BSA fouled, modified (CAI-U) and unmodified (CAI) membranes. Figure 12 shows that protein

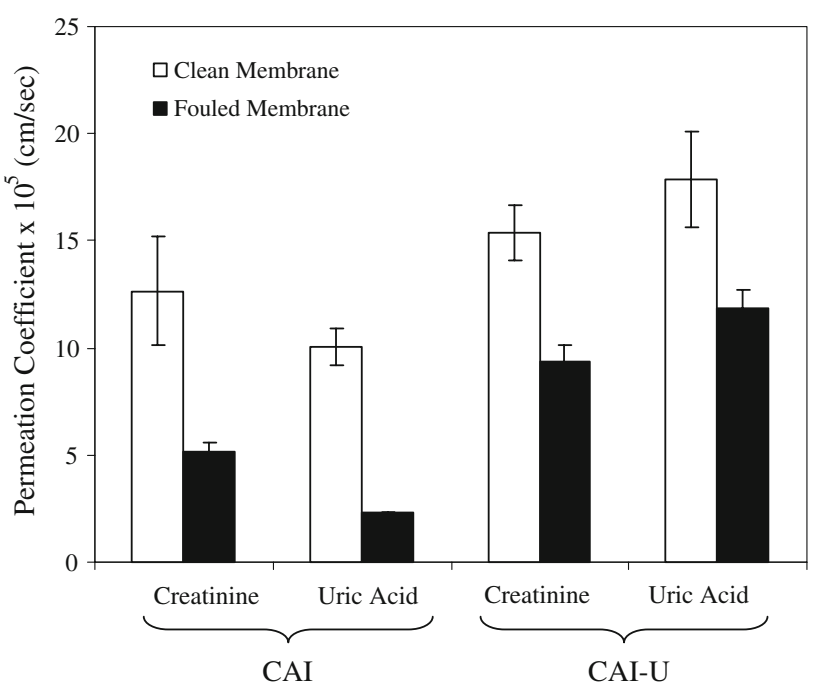

Fig. 12 The influence of protein adsorption on the permeation coefficients of uric acid and creatinine through unmodified (CAI) and modified (CAI-U) membranes

fouling on the membranes caused a decrease in the permeation coefficients of both solutes. Urease immobilization reduced the decrease in the permeation coefficients of uric acid and creatinine by a factor of 2.8 and 1.5 , respectively. Similarly, the influence of protein adsorption on the efficiency of urea removal from the donor compartment is less pronounced when immobilized urease-CA membrane was used. Due to protein fouling, $\%$ removal of urea from the donor compartment in $1 \mathrm{~h}$ decreased by $27.5 \%$ and $12.5 \%$ through unmodified and modified CA membranes, respectively. The experimental data for urea removal with the modified CA membrane were regressed with the mathematical model and as shown in Fig. 13, the model provides reasonably good correlation of the data collected for BSA fouled membranes as well. The Thiele modulus value was found to decrease from 1.08 to 0.44 due to adsorption of $\mathrm{BSA}$ on the CA membrane. As a result, the transport of urea is dominantly controlled by enzymatic reaction, hence, the diffusivity of urea in the modified CA membrane does not change due to protein fouling. The enzyme inactivation constant, $k$, for BSA fouled CA membrane was found to be much smaller than that of the clean CA membrane. This is due to preliminary inactivation of urease during the fouling experiment. Thus, no more loss in catalytic activity of BSA fouled CA membrane occurs during the permeation experiment.

\subsection{Mechanical properties of CA membranes}

Mechanical properties of the CA membranes were evaluated in terms of tensile strength and Young's modulus values and the results are listed in Table 4. The tensile 


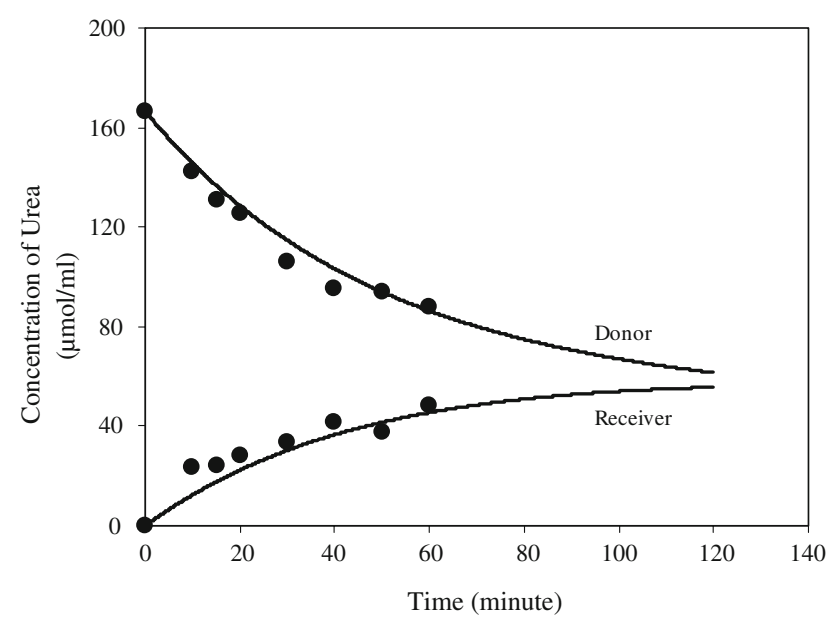

Fig. 13 The comparison of model predictions with the experimental data for the change of urea concentration in donor and receiver compartments with respect to time when protein fouled modified CA membrane was used. The symbols correspond to experimental data and the lines represent model predictions. The enzyme inactivation constant, $k$, regressed is $0.00005 \mathrm{~min}^{-1}$

Table 4 Mechanical properties of modified and unmodified CA membranes

\begin{tabular}{lccl}
\hline $\begin{array}{l}\text { Code of the } \\
\text { membrane }\end{array}$ & $\begin{array}{l}\text { Maximum tensile } \\
\text { stress }\left(\mathrm{kN} / \mathrm{m}^{2}\right)\end{array}$ & $\begin{array}{l}\text { Young modulus } \\
\left(\mathrm{kN} / \mathrm{m}^{2}\right)\end{array}$ & $\begin{array}{l}\text { Thickness } \\
\text { of the } \\
\text { membrane } \\
(\mu \mathrm{m})\end{array}$ \\
\hline CAI & $3750 \pm 880$ & $2568 \pm 1016$ & 27.94 \\
CAII & $19530 \pm 5414$ & $7946 \pm 2056$ & 19.66 \\
CAIII & $58584 \pm 7551$ & $19352 \pm 4557$ & 19.16 \\
CAI-U & $6720 \pm 1262$ & $2734 \pm 751$ & 16.71 \\
\hline
\end{tabular}

strength of the membranes increased more than one order of magnitude by increasing CA concentration in the casting solution from $5 \%$ to $15 \%$. This is mainly due to reduced pore sizes and much more dense structure of the membranes which can support higher load. Young's modulus was also found to increase with increased CA content in the membranes since dense structures become stiffer compared to porous structures. The results have shown that the addition of $0.5 \%$ urease into $5 \%$ CA solution increased the tensile strength of the membrane by a factor of 1.8 , while the Young's modulus remained approximately the same. This can be attributed to disappearance of macrovoids and blockage of some of the pores present in CAI membranes with the immobilization of urease as shown by the SEM pictures in Figs. 4 and 9, respectively.

\section{Conclusion}

In this study, asymmetric cellulose acetate membranes were prepared by dry phase inversion method and modified through urease enzyme immobilization. Before the modification step, the effect of composition of the initial casting solution on the permeation rates and the mechanical properties of the membranes were investigated. With increased CA content in the casting solution, the permeation coefficients of all model solutes decreased while the percentage of dense skin layer, tensile strength and Young's modulus values of the membranes increased. The membrane prepared with 5\% CA was selected for enzyme immobilization due to its high permeation rates and sufficient mechanical strength. The transport rates of the uric acid and creatinine through modified CA membrane slightly enhanced over the regular unmodified one due to a change in the structure of the membrane. Urease immobilization also enhanced the rate of removal of urea mainly due to its decomposition and caused a decrease in the protein adsorption capacity of the unmodified membranes without any loss in the mechanical properties. The enhancement in the transport rate of urea through immobilized-urease membrane was also verified by the mathematical model predictions. Although the improvement in the clearance values obtained with our enzyme immobilization strategy is moderate, it is possible to increase the catalytic performance of the membranes by immobilizing the enzyme on the surface with the strong covalent bonding. It is also interesting to investigate the influence of enzyme immobilization technique on the protein adsorption capacity of the membranes. To our knowledge, this is the first study which suggests enzyme immobilization as a possible technique to prepare membranes with reduced protein adsorption capacities along with improved transport properties. Thus, immobilized urease-membranes can be used to improve the efficiency of hemodialysis operation.

Acknowledgments The authors like to thank Izmir Institute of Technology for the financial support through Grant 2005 IYTE 32. We also gratefully acknowledge Prof. Ahmet Yemenicioglu of İzmir Institute of Technology Department of Food Engineering for useful discussions.

\section{References}

1. Sun S, Yue Y, Huang X, Meng D. Protein adsorption on bloodcontact membranes. J Membr Sci. 2003;222:3-18. doi: 10.1016/S0376-7388(03)00313-2.

2. Ishihara K, Fukumoto K, Iwasaki Y, Nakabayashi N. Modification of polysulfone with phospholipid polymer for improvement of the blood compatibility. 1. Surface characterization. Biomaterials. 1999;20:1545-51. doi:10.1016/S0142-9612(99)00052-6.

3. Ishihara K, Fukumoto K, Iwasaki Y, Nakabayashi N. Modification of polysulfone with phospholipid polymer for improvement of the blood compatibility. Part 2. Protein adsorption and platelet adhesion. Biomaterials. 1999;20:1553-9. doi:10.1016/S01429612(98)00206-3. 
4. Hasegawa T, Iwasaki Y, Ishihara K. Preparation and performance of protein-adsorption-resistant asymmetric porous membrane composed of polysulfone/phospholipid polymer blend. Biomaterials. 2001;22:243-51. doi:10.1016/S0142-9612(00)00180-0.

5. Ye SH, Watanabe J, Iwasaki Y, Ishihara K. Antifouling blood purification membrane composed of cellulose acetate and phospholipid polymer. Biomaterials. 2003;24:4143-52. doi: 10.1016/S0142-9612(03)00296-5.

6. Ye SH, Watanabe J, Iwasaki Y, Ishihara K. Novel cellulose acetate membrane blended with phospholipid polymer for hemocompatible filtration system. J Membr Sci. 2002;210:411-21. doi:10.1016/S0376-7388(02)00421-0.

7. Ye SH, Watanabe J, Iwasaki Y, Ishihara K. In situ modification on cellulose acetate hollow fiber membrane modified phospholipid polymer for biomedical application. J Membr Sci. 2005;249:133-41. doi:10.1016/j.memsci.2004.10.006.

8. Ye SH, Watanabe J, Takai M, Iwasaki Y, Ishihara K. Design of functional hollow fiber membranes modified with phospholipid polymers for application in total hemopurification system. Biomaterials. 2005;26:5032-41. doi:10.1016/j.biomaterials.2005. 01.049 .

9. Torrestiana-Sanchez B, Ortiz-Basurto RI, Brito-De La Fuente E. Effect of nonsolvents on properties of spinning solutions and polyethersulfone hollow fiber ultrafiltration membranes. J Membr Sci. 1999;152:19-28. doi:10.1016/S0376-7388(98)00172-0.

10. Castro RP, Cohen Y, Monbouquette HG. Silica-supported polyvinylpyrrolidone filtration membranes. J Membr Sci. 1996;115: 179-90. doi:10.1016/0376-7388(96)00019-1.

11. Freij-Larsson C, Jannasch P, Wesslén B. Polyurethane surfaces modified by amphiphilic polymers: effects on protein adsorption. Biomaterials. 2000;21:307-15. doi:10.1016/S0142-9612(99) 00195-7.

12. Lee JH, Ju YM, Kim DM. Platelet adhesion onto segmented polyurethane film surfaces modified by addition and crosslinking of PEO-containing block copolymers. Biomaterials. 2000;21:68391. doi:10.1016/S0142-9612(99)00197-0.

13. Zhang F, Kang ET, Neoha KG, Wang P, Tan KL. Surface modification of stainless steel by grafting of poly(ethylene glycol) for reduction in protein adsorption. Biomaterials. 2001;22:15418. doi:10.1016/S0142-9612(00)00310-0.

14. Kilduft JE, Mattaraj S, Pieracci JP, Belfort G. Photochemical modification of poly(ether sulfone) and sulfonated poly(sulfone) nanofiltration membranes for control of fouling by natural organic matter. Desalination. 2000;132:133-42. doi:10.1016/ S0011-9164(00)00142-9.

15. Pieracci JP, Crivello JV, Belfort G. Increasing membrane permeability of UV-modified poly(ether sulfone) ultrafiltration membranes. J Membr Sci. 2002;202:1-16. doi:10.1016/S03767388(01)00624-X.

16. Wavhal DS, Fisher ER. Hydrophilic modification of polyethersulfone membranes by low temperature plasma-induced graft polymerization. J Membr Sci. 2002;209:255-69. doi:10.1016/ S0376-7388(02)00352-6.

17. Song YQ, Sheng J, Wei M, Yuan XB. Surface modification of polysulfone membranes by low-temperature plasma-graft poly(ethylene glycol) onto polysulfone membranes. J Appl Polym Sci. 2000;78:979-85. doi:10.1002/1097-4628(20001031)78:5< 979:AID-APP60>3.0.CO;2-U.

18. Iwata H, Ivanchenko MI, Miyaki Y. Preparation of anti-oil stained membrane by grafting polyethylene-glycol macromer onto polysulfone membrane. J Appl Polym Sci. 1994;54:125-8. doi:10.1002/app.1994.070540113.

19. Ulbricht M, Belfort G. Low temperature surface modifications of polyacrylonitrile ultrafiltration membranes. 1. Plasma treatment effects. J Appl Polym Sci. 1995;56:325-43. doi:10.1002/app. 1995.070560304.
20. Pall DB. Gsell TC US Patent 4 1989;880:548.

21. Ulbricht M, Riedel M. Ultrafiltration membrane surfaces with grafted polymer 'tentacles': preparation. Biomaterials. 1998;19: 1229-37. doi:10.1016/S0142-9612(98)00029-5.

22. Yamagishi H, Crivello JV, Belfort G. Development of a novel photochemical technique for modifying poly(arylsulfone) ultrafiltration membranes. J Membr Sci. 1995;105:237-47. doi: 10.1016/0376-7388(95)00063-I.

23. Kaeselev B, Pieracci J, Belfort G. Photoinduced grafting of ultrafiltration membranes: comparison of poly(ether sulfone) and poly(sulfone). J Membr Sci. 2001;194:245-61. doi:10.1016/ S0376-7388(01)00544-0.

24. Brink LES, Elbers SJG, Robbertsen T, Both P. The anti-fouling action of polymers preadsorbed on ultrafiltration and microfiltration membranes. J Membr Sci. 1993;76:281-91. doi: 10.1016/0376-7388(93)85225-L.

25. Kim KJ, Fane AG, Fell CJD. The performance of ultrafiltration membranes pretreated by polymers. Desalination. 1988;70:229 49. doi:10.1016/0011-9164(88)85057-4.

26. Higuchi A, Sugiyama K, Yoon BO, Sakurai M, Hara M, Sumita $\mathrm{M}$, et al. Serum protein adsorption and platelet adhesion on pluronic ${ }^{\mathrm{TM}}$-adsorbed polysulfone membranes. Biomaterials. 2003;24:3235-45. doi:10.1016/S0142-9612(03)00186-8.

27. Lewis AL, Hughes PD, Kirkwood LC, Leppard SW, Redman RP, Tolhurst LA, et al. Synthesis and characterisation of phosphorylcholine-based polymers useful for coating blood filtration devices. Biomaterials. 2000;21:1847-59. doi:10.1016/S01429612(00)00055-7.

28. Cenni E, Cavedagna D, Falsone G, Mari G, Pizzaferrato A. Numerical and functional modifications in platelets induced by polyester coated by a hydrophilic polymer. Biomaterials. 1993;14:588-90. doi:10.1016/0142-9612(93)90176-3.

29. Ueda T, Oshida H, Kurita K, Ishihara K, Nakabayashi N. Preparation of 2-methacryloyloxyethyl phosphorylcholine copolymers with alkyl methacrylates and their blood compatibility. Polym J. 1992;24:1259-69. doi:10.1295/polymj.24.1259.

30. Olsson P, Sanchez J, Mollnes TE, Riesenfeld J. On the blood compatibility of endpoint immobilized heparin. J Biomater Sci Polym Ed. 2000;11:1261-73. doi:10.1163/156856200744192.

31. Chen Z, Zhang R, Kodama M, Nakaya T. Anticoagulant surface prepared by the heparinization of ionic polyurethane film. J Appl Polym Sci. 2000;76:382-90. doi:10.1002/(SICI)1097-4628 (20000418)76:3<382:AID-APP13>3.0.CO;2-A.

32. Rollason G, Sefton MV. Inactivation of thrombin in heparin-PVA coated tubes. J Biomater Sci Polym Ed. 1989;1:31-41. doi: 10.1163/156856289X00046.

33. Yang MC, Lin WC. Protein adsorption and platelet adhesion of polysulfone membrane immobilized with chitosan and heparin conjugate. Polym Adv Technol. 2003;14:103-13. doi:10.1002/ pat.337.

34. Yang MC, Lin WC. Surface modification and blood compatibility of polyacrylonitrile membrane with immobilized chitosan-heparin conjugate. J Polym Res. 2002;9:201-6. doi:10.1023/A: 1021347810130.

35. Kang IK, Kwon OH, Kim MK, Lee YM, Sung YK. Preparation and surface characterization of functional group-grafted and heparinimmobilized polyurethanes by plasma glow discharge. Biomaterials. 1996;17:841-7. doi:10.1016/0142-9612(96)81422-0.

36. Han DK, Park KD, Ahn KD, Jeong SY, Kim YH. Preparation and surface characterization of PEO-grafted and heparin-immobilized polyurethanes. J Biomed Mater Res Appl Biomater. 1989;23:87104. doi: $10.1002 / \mathrm{jbm} .820231309$.

37. Lin WC, Liu TY, Yang MC. Hemocompatibility of polyacrylonitrile dialysis membrane immobilized with chitosan and heparin conjugate. Biomaterials. 2004;25:1947-57. doi:10.1016/ j.biomaterials.2003.08.027. 
38. Zhao C, Liu X, Rikimaru S, Nomizu M, Nishi N. Surface characterization of polysulfone membranes modified by DNA immobilization. J Membr Sci. 2003;214:179-89. doi:10.1016/ S0376-7388(02)00524-0.

39. Liu TY, Lin WC, Huang LY, Chen SY, Yang MC. Hemocompatibility and anaphylatoxin formation of protein-immobilizing polyacrylonitrile hemodialysis membrane. Biomaterials. 2005;26: 1437-44. doi:10.1016/j.biomaterials.2004.04.039.

40. Yang MC, Lin CC. Urea permeation and hydrolysis through hollow fiber dialyzer immobilized with urease. Biomaterials. 2001;22:891-6. doi:10.1016/S0142-9612(00)00251-9.

41. Lin CC, Yang MC. Urea permeation and hydrolysis through hollow fiber dialyzer immobilized with urease: storage and operation properties. Biomaterials. 2003;24:1989-94. doi: 10.1016/S0142-9612(02)00611-7.

42. Weatherburn MW. Phenol-hypochlorite reaction for determination of ammonia. Anal Chem. 1967;39:971-4. doi:10.1021/ ac60252a045.

43. Bradford MM. A rapid and sensitive method for the quantitation of microgram quantities of protein utilizing the principle of protein-dye binding. Anal Biochem. 1976;72:248-54. doi: 10.1016/00032697(76)90527-3.

44. Bódalo A, Gómez JL, Gómez E, Máximo MF, Montiel MC. Study of L-aminoacylase deactivation in an ultrafiltration membrane reactor. Enzyme Microb Technol. 2004;35:261-6. doi: 10.1016/j.enzmictec.2004.05.003.

45. Cussler EL. Diffusion mass transfer in fluid systems. 2nd ed. Cambridge University Press; 1997. p. 23.

46. Pekny MR, Greenberg AR, Khare V, Zartman J, Krantz WB, Todd P. Macrovoid pore formation in dry-cast cellulose acetate membranes: buoyancy studies. J Membr Sci. 2002;205:11-21. doi:10.1016/S0376-7388(02)00033-9.

47. Pekny MR, Zartman J, Krantz WB, Greenberg AR, Todd P. Flow-visualization during macrovoid pore formation in dry-cast cellulose acetate membranes. J Membr Sci. 2003;211:71-90. doi: 10.1016/S0376-7388(02)00381-2.

48. Krajewska B, Leszko M, Zaborska W. Urease immobilized on chitosan membrane: preparation and properties. J Chem Technol Biotechnol. 1990;48:337-50. doi:10.1002/jctb.280480309.

49. Ling CC, Yang MC. Cholesterol oxidation using hollow fiber dialyzer immobilized with cholesterol oxidase: effect of storage and reuse. Biomaterials. 2003;24:549-57. doi:10.1016/S01429612(02)00366-6.

50. Giorno L, Drioli E. Biocatalytic membrane reactors: applications and perspectives. Trends Biotechnol. 2000;18:339-49. doi: 10.1016/S0167-7799(00)01472-4. 